\title{
Carbonic anhydrase VII is S-glutathionylated without loss of catalytic activity and affinity for sulfonamide inhibitors
}

\author{
Emanuela Truppo a, Claudiu T. Supuran ${ }^{\text {b,* }}$, Annamaria Sandomenico a ${ }^{\text {, Daniela Vullo }}{ }^{\mathrm{b}}$, Alessio Innocenti ${ }^{\mathrm{b}}$, \\ Anna Di Fiore ${ }^{a}$, Vincenzo Alterio ${ }^{\text {a }}$, Giuseppina De Simone ${ }^{a}$, Simona M. Monti ${ }^{\text {a,* }}$ \\ a Istituto di Biostrutture e Bioimmagini-CNR, via Mezzocannone 16, 80134 Napoli, Italy \\ ${ }^{\mathrm{b}}$ Università degli Studi di Firenze, Polo Scientifico, Laboratorio di Chimica Bioinorganica, Rm. 188, Via della Lastruccia 3, 50019 Sesto Fiorentino (Florence), Italy
}

\section{A R T I C L E I N F O}

\section{Article history:}

Received 19 July 2011

Revised 30 December 2011

Accepted 31 December 2011

Available online 5 January 2012

\section{Keywords:}

Carbonic anhydrase VII

Glutathionylation

CA inhibitors

Catalytic activity

Cysteine reactivity

\begin{abstract}
A B S T R A C T
Human carbonic anhydrase (CA, EC 4.2.1.1) VII is a cytosolic enzyme with high carbon dioxide hydration activity. Here we report an unexpected S-glutathionylation of hCA VII which has also been observed earlier in vivo for hCA III, another cytosolic isoform. Cys183 and Cys217 were found to be the residues involved in reaction with glutathione for hCA VII. The two reactive cysteines were then mutated and the corresponding variant (C183S/C217S) expressed. The native enzyme, the variant and the S-glutathionylated adduct (sgCA VII) as well as hCA III were fully characterized for their $\mathrm{CO}_{2}$ hydration, esterase/phosphatase activities, and inhibition with sulfonamides. Our findings suggest that hCA VII could use the in vivo S-glutathionylation to function as an oxygen radical scavenger for protecting cells from oxidative damage, as the activity and affinity for inhibitors of the modified enzyme are similar to those of the wild type.
\end{abstract}

(c) 2012 Elsevier Ltd. All rights reserved.
Carbonic anhydrases (CAs) are ubiquitous metallo-enzymes that catalyze the reversible hydration of carbon dioxide to bicarbonate and protons. ${ }^{1-3}$ In mammals, 16 isozymes have been described with different catalytic activity, subcellular localization and tissue distribution. Among these CA I-III, VII, and CA XIII are cytosolic, CA IV, IX, XII, XIV, and CA XV are membrane-bound, CA VA and CA VB are mitochondrials, and finally CAVI is a secreted isozyme. ${ }^{1}$ These enzymes play a crucial physiological role in processes such as acid-base homeostasis, electrolyte secretion, ion transport, biosynthetic reactions, bone resorption and tumorigenity. ${ }^{1-3}$

A very intriguing feature of this highly investigated enzyme family concerns the rather high number of isozymes in mammals, ${ }^{1-3}$ their very different catalytic activities for the physiologic reaction (Fig. 1), and the question of whether some of them might possess other functions apart from their role in the physiological reaction of carbon dioxide hydration. In this context, several studies have demonstrated that some CAs are involved in other hydrolytic processes which presumably involve non-physiological substrates, such as hydration of cyanate to carbamic acid, cyanamide to urea, aldehyde hydration to gem-diols, and some carboxylic, or sulfonic acid esters. ${ }^{4-12}$ Recently, also esterase, phosphatase and sulfatase activities have been investigated for

\footnotetext{
* Corresponding authors. Tel.: +39 0554573005 (C.T.S.); +39 0812534583 (S.M.M.).

E-mail addresses: claudiu.supuran@unifi.it (C.T. Supuran), marmonti@unina.it (S.M. Monti).
}

some cytosolic isozymes, namely hCA I, hCA II, mCA XIII ( $\mathrm{h}=\mathrm{hu}-$ man, $m=$ murine), demonstrating that all these isoforms have esterase and phosphatase activity with MCA XIII resulting the most active. $^{13}$ Moreover, the observation that these activities were inhibited by sulfonamide inhibitors proved that the zinc hydroxide mechanism responsible for the $\mathrm{CO}_{2}$ hydration activities of these enzymes was also responsible for their esterase/phosphatase activity. On the contrary, none of the three investigated isozymes showed sulfatase activity with 4-nitrophenyl sulfate as substrate. ${ }^{13}$

In this Letter, we focused our study on cytosolic hCA VII, one of the least investigated and understood cytosolic isoforms. Similar to hCA II, hCA VII shows very high efficiency as catalyst for hydration of carbon dioxide (Table 1), being 10-50 times more active compared to hCA I and hCA XIII. ${ }^{1,14 a}$ However, in contrast to hCA II which is widely spread in human tissues, CA VII has a more limited distribution, being localized mainly in some brain tissues of humans and rats, ${ }^{14 a, b, 15}$ and in stomach, duodenum, colon, liver and skeletal muscle of mice. ${ }^{16}$ The enzyme was also recently characterized by X-ray crystallography showing that as observed for other $\alpha$-CAs, its structure consists of a central 10 -stranded $\beta$-sheet surrounded by several helices and additional $\beta$-strands. The active site is located in a conical cavity, with the catalytic zinc ion at the bottom. ${ }^{17}$

CA VII has been pointed out for its contribution to generate neuronal excitation, ${ }^{18}$ establishing a GABAergic transmission functionally excitatory by providing bicarbonate anion, which can mediate current through channels coupled to $\mathrm{GABA}_{\mathrm{A}}$ receptors. ${ }^{18}$ This activity is suppressed when treated with membrane-permeating drugs, 

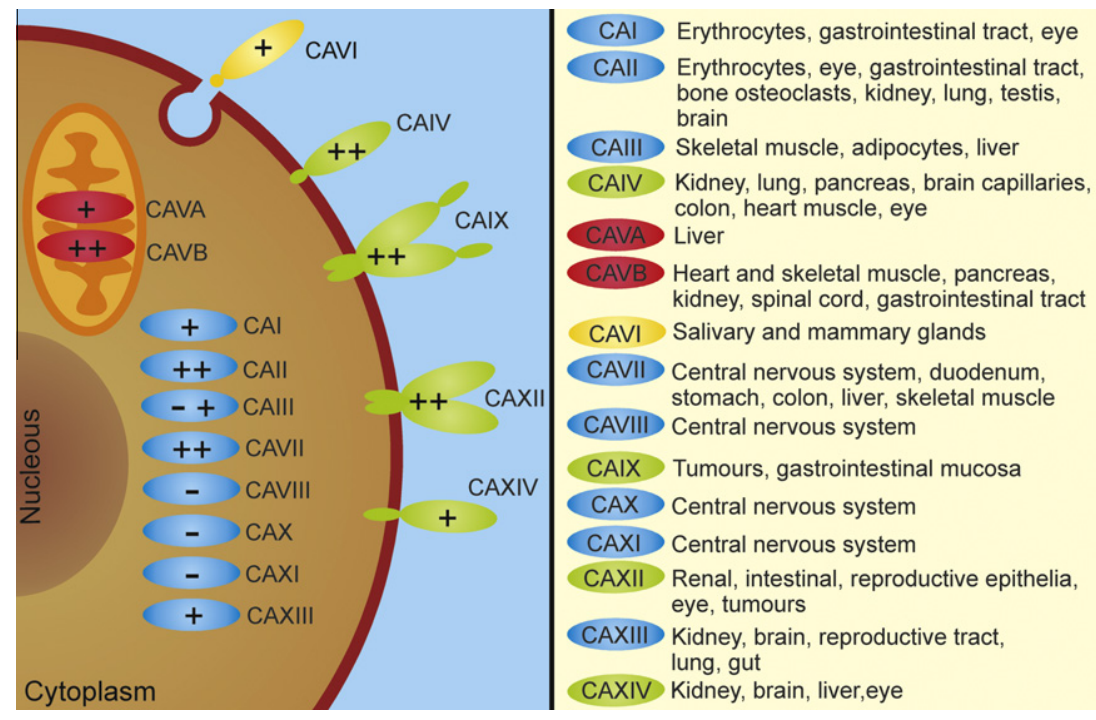

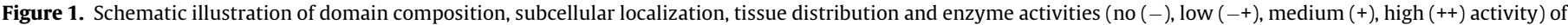

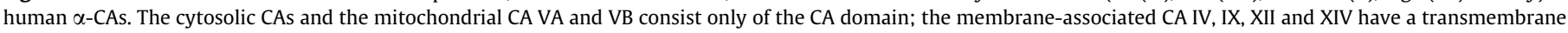

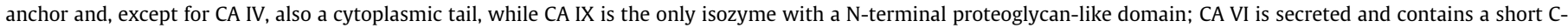
terminal extension.

Table 1

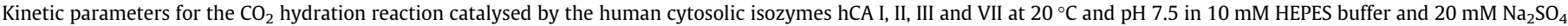

\begin{tabular}{|c|c|c|c|c|c|c|}
\hline Isozyme & Activity level & $k_{\text {cat }}\left(\mathrm{s}^{-1}\right)$ & $k_{\text {cat }} / K_{\mathrm{M}}\left(\mathrm{M}^{-1} \mathrm{~s}^{-1}\right)$ & $K_{\mathrm{M}}(\mathrm{mM})$ & $K_{\mathrm{I}}(\mathrm{AZA})(\mathrm{nM})$ & Ref. \\
\hline hCA I & Moderate & $2.0 \times 10^{5}$ & $5.0 \times 10^{7}$ & 4.0 & 250 & 13 \\
\hline hCA II & Very high & $1.4 \times 10^{6}$ & $1.5 \times 10^{8}$ & 9.3 & 12 & 13 \\
\hline hCA III & Very low & $1.4 \times 10^{4}$ & $2.5 \times 10^{5}$ & 52 & 240,000 & $14 \mathrm{c}$ \\
\hline $\mathrm{mCA} \mathrm{VII}^{\mathrm{a}}$ & High & $9.4 \times 10^{5}$ & $7.6 \times 10^{7}$ & 12.3 & 16 & 40 \\
\hline hCA VII & - & $(7.9 \pm 0.1) \times 10^{5}$ & $(7.2 \pm 0.1) \times 10^{7}$ & $11.0 \pm 0.3$ & $2.8 \pm 0.1$ & $\mathrm{a}$ \\
\hline C183S/C217S & - & $(7.0 \pm 0.2) \times 10^{5}$ & $(6.5 \pm 0.1) \times 10^{7}$ & $10.8 \pm 0.5$ & $3.0 \pm 0.3$ & $\mathrm{a}$ \\
\hline sgCA VII & - & $(8.0 \pm 0.2) \times 10^{5}$ & $(8.0 \pm 0.2) \times 10^{7}$ & $10.0 \pm 0.4$ & $2.7 \pm 0.3$ & $\mathrm{a}$ \\
\hline
\end{tabular}

Inhibition data with the clinically used sulfonamide acetazolamide AZA (5-acetamido-1,3,4-thiadiazole-2-sulfonamide) are also provided.

${ }^{*} \mathrm{~h}=$ human, $\mathrm{m}=$ murine isoform.

a This work.

supporting the implication of hCA VII in neuronal excitation and seizures. ${ }^{15}$ More recently a role of this enzyme in the control of neuropathic pain has also been proposed, suggesting that its inhibition may constitute a new pharmacologic mechanism in designing pain killers useful for neuropathic pain. ${ }^{19}$

As part of a general research project based on the structure based drug design of isoform-selective CA inhibitors (CAIs), we have undertaken a complete biochemical and catalytic characterization of hCA VII. The full-length hCA VII was cloned into the pGex-4T-3 vector and the protein was expressed and affinity-purified on GSTrap resin as previously described. ${ }^{17}$ After pAMBS affinity chromatography, ${ }^{20}$ the final step of purification was performed on a Superdex 75 leading to a unique peak corresponding to a monomer. hCA VII purity and molecular weight were further characterized by electrospray ionization mass spectrometry. ${ }^{21}$ An ESI LC MS spectrum of purified hCA VII is shown in Figure 2A. Two major peaks were detected, none of them corresponding to the expected one. Surprisingly, these two peaks showed an incremented molecular weight of $305 \mathrm{Da}$ and $610 \mathrm{Da}$ compared to the theoretical one which disappeared when the sample was treated with DTT. In this case only one peak occurred with an experimental mass identical to the expected one (hCA VII theoretical molecular weight $30100.8 \mathrm{Da}$ ) (Fig. 2B). The observed mass increment of $305 \mathrm{Da}$ and $305 \times 2$ Da was thus ascribed to glutathionylation of two cysteine residues occurred during elution from the glutathione-Sepharose column with a buffer containing
$10 \mathrm{mM}$ GSH. hCA VII contains four cysteine residues in its sequence at positions $54,178,183$, and 217 (numbering refers to the CA II sequence). In order to identify which of the four cysteines were involved in the formation of the covalent adduct with GSH, wt GSH eluted protein was digested with trypsin ${ }^{23}$ and the peptide mixture directly analyzed by LC-ESI-MS/MS, with sufficient accuracy to enable unambiguous identification of the tryptic peptides. ${ }^{22,24,25}$ Fragments Cys183-Arg189 and Glu214-Arg221, containing Cys183 and Cys217, respectively, eluted only as adducts with GSH, showing that both cysteines were completely modified. On the contrary, fragments Gln28-Arg76 and Ala174-Lys182, containing Cys54 and Cys178 respectively, were not identified by molecular mass and MS/MS sequencing, but were revealed only after DTT incubation. In this case two more species were generated with $\mathrm{MH}^{+}$ signals at 1041.5 and 5369.5, which were assigned to the reduced peptides Ala174-Lys182 and Gln28-Arg76, respectively. Altogether these data clearly suggest that among the four cysteines present in the amino acid sequence, Cys183 and Cys217 were those involved in S-glutathionylation, whereas Cys54 and Cys178 were involved in the formation of an intramolecular disulfide bridge. ${ }^{21 \mathrm{~b}}$ The disulfide bond was evidenced also by X-ray structural analysis of this enzyme, ${ }^{17}$ and subsequently reported by Bootorabi and co-workers. ${ }^{16}$ However, the observation that disulfide bonds are extremely rare in cytosolic proteins ${ }^{26}$ and that Cys54 and Cys178 are not conserved within the human cytosolic CA family, suggests that this disulfide bond could be an artifact generated by the oxidizing 

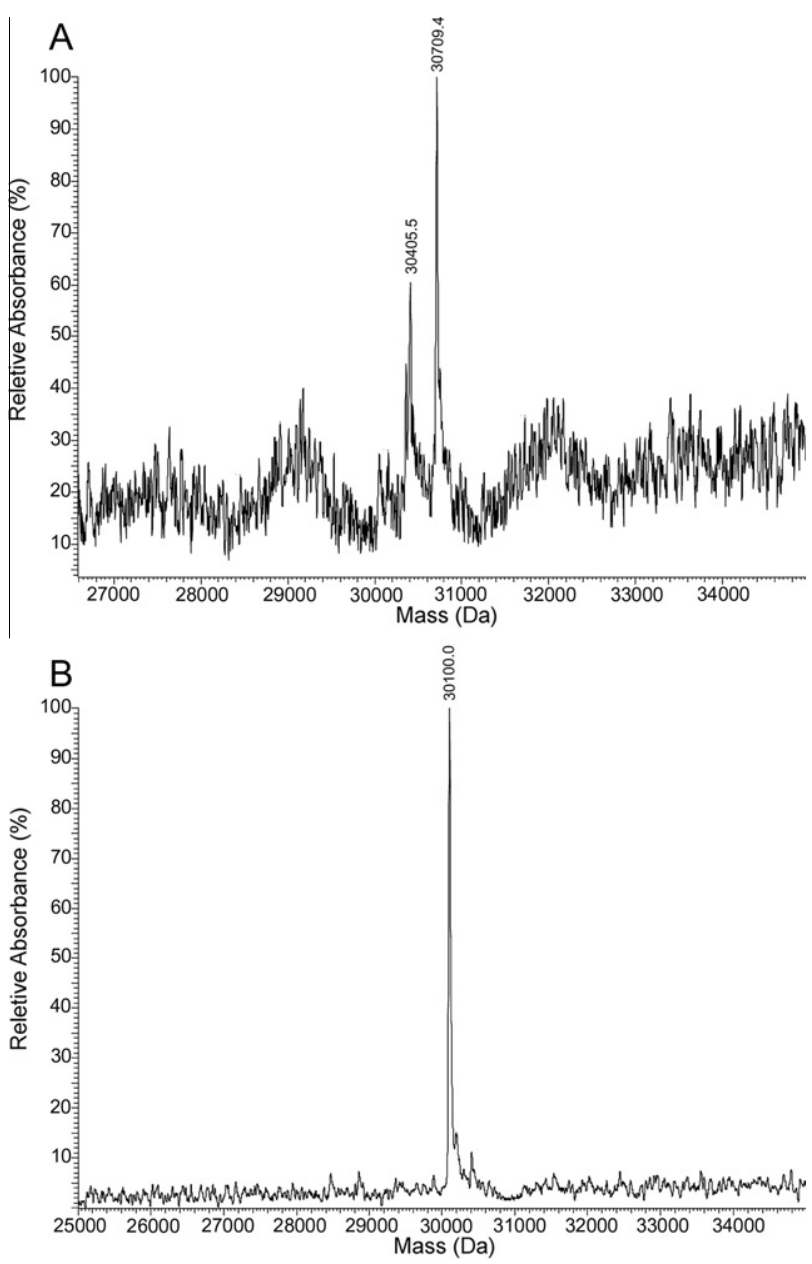

Figure 2. LC-ESI-MS of purified hCA VII. (A) Deconvoluted mass spectrum of purified hCAVII showed the presence of two distinct peaks with a greater mass of 305 and $305 * 2$ compared to the expected one (theoretical mw $30100.8 \mathrm{Da}$ ). (B) After treatment with reducing agent DTT the two peaks disappeared leading to a unique peak of 30100.0 Da.

conditions that arise during protein handling and is not present in hCA VII under physiological conditions. Further studies are needed to clarify this point. On the contrary, interesting considerations can be done on the observed in vitro S-glutathionylation of Cys183 and Cys217 in hCA VII. This covalent modification can be ascribed to a partial oxidation of cysteines to sulfenic acids or thiol radicals followed by reaction with $\mathrm{GSH},{ }^{27}$ used for eluting the protein from GSTrap. Therefore, both the high reactivity of Cys183 and Cys217 and the high GSH concentration in the experimental conditions can be the origin of such phenomena. However, it is worth noting that this in vitro spontaneous reaction mimics S-glutathionylation observed in vivo for another CA isozyme, namely CA III, which however possesses a very low $\mathrm{CO}_{2}$ hydrase activity (Table 1). ${ }^{1,14 a}$ In particular, rat liver CA III has been shown to be S-glutathionylated in vivo ${ }^{28-30}$ at two cysteine residues in position 183 and $188 .^{31}$ Moreover, microarray analysis of skeletal muscle of wild type and CA III-deficient knockout mice suggested that CA III, undergoing rapid reversible S-glutathionylation or irreversible oxidation in mildly and exhaustively stressed muscle, has a possible role in the glutathione-mediated antioxidative system. ${ }^{32}$ These data were also in agreement with the proposal of Raisanen and co-workers ${ }^{33}$ that CA III functions as an oxygen radical scavenger to protect cells from oxidative damage and could explain the increased sensitivity to $\mathrm{H}_{2} \mathrm{O}_{2}$ of CA III knockdown Rat1 or Evi1-expressing Rat1 cells. ${ }^{34}$
Indeed, hCA VII and hCA III presents several analogies: in particular, both enzymes are cytosolic and are localized in tissues that have a high oxygen consumption rate, such as skeletal muscle, liver and brain (see Fig. 1). Furthermore, compared to the other cytosolic CA isoforms both enzymes incorporate a high number of cysteines in their sequence (Fig. 3): hCA III has five cysteines, hCA VII four, whereas the others only have one (hCA I, hCA II, and hCA XIII). It is also worth noting that one of the cysteines which has been reported to be glutathionylated for hCA III, namely Cys 183, is conserved also in hCA VII (Fig. 3). All these considerations strongly indicate that the S-glutathionylation observed in vitro for hCA VII could be present also in vivo, as in the case observed for the related isoform hCA III. Thus, to get more insights into the role of the covalent modification of the enzyme, we measured kinetic parameters for the canonical $\left(\mathrm{CO}_{2} \text { hydration activity }\right)^{35}$ and non-canonical (esterase, phosphatase and sulfatase activities) $)^{37,38}$ hydrolytic reactions for the wild type enzyme purified in absence of GSH (thus lacking the covalent modification), the glutathionylated enzyme, and a variant form of the protein in which both reactive cysteines were mutated in serines (C183S/C217S). ${ }^{40}$ hCA III, prepared as described earlier, ${ }^{14 c}$ was also included in such experiments as its esterase and phosphatase activities have not yet been reported as far as we know.

Data of Table 1 show that the mutation of the two Cys residues to Ser or their S-glutathionylation does not affect significantly the $\mathrm{CO}_{2}$ hydrase activity and affinity for acetazolamide, a sulfonamide inhibitor of CA enzymes. Indeed, the kinetic parameters of the three enzymes are almost identical (within the limits of the experimental errors) as are their inhibition constants for the inhibitor. This is not so surprising, considering the fact that the modified Cys residues are not within the enzyme active site. It should be also noted from the data of Table 1 that hCA III has very low catalytic activity as $\mathrm{CO}_{2}$ hydrase in contrast to all other isoforms/mutants investigated here.

Unexpectedly, we observed that the wild type enzyme, its C183S/C217S variant, and the S-glutathionylated enzyme are excellent esterases with 4-nitrophenyl acetate as substrate (Table 2). Indeed, compared to other cytosolic CAs, such as CA I, II and XIII, the hCA VII variants investigated here were around 3 orders of magnitude better esterases. As far as we know, this is the highest esterase activity reported so far for any CA isoform. This extremely high esterase activity prompts us to speculate that hCA VII may have an additional catalytic activity in vivo, in addition to the $\mathrm{CO}_{2}$ hydrase, but this warrants further studies for determining which other esters may act as substrates for this enzyme. It is interesting to note that unlike the $\mathrm{CO}_{2}$ hydrase activity, for the esterase activity described in Table 2, the wild type enzyme, C183S/C217S variant and sgCA VII have slightly different $k_{\text {cat }}$ and $K_{\mathrm{M}}$ values, which is rather difficult to explain. However, as we stressed above, all these three different enzymes are highly effective esterases, and their activity is inhibited by the sulfonamide inhibitor acetazolamide, with $\mathrm{IC}_{50}$ values in the range of 170 $357 \mathrm{nM}$ (Table 2). It should be also noted that among all cytosolic isoforms hCA III is also the least effective esterase with 4-nitrophenyl acetate as substrate and is also the least inhibited by the sulfonamide inhibitor acetazolamide ( $\mathrm{IC}_{50}$ of $7.84 \mu \mathrm{M}$, Table 2 ).

The phosphatase activity of hCA VII and of its variants investigated here were also quite interesting (Table 3). The wt enzyme and its glutathionylated/mutant forms were at least one order of magnitude better phosphatases compared to CA I, II, III and XIII investigated earlier. Again the difference of activity between the three variants of hCA VII investigated here was rather small, but this activity was inhibited by acetazolamide proving that it is due to the zinc hydroxide species from the enzyme active site. Unexpectedly, hCA III was a more effective phosphatase with 4nitrophenyl phosphate compared to hCA II, one of the best 


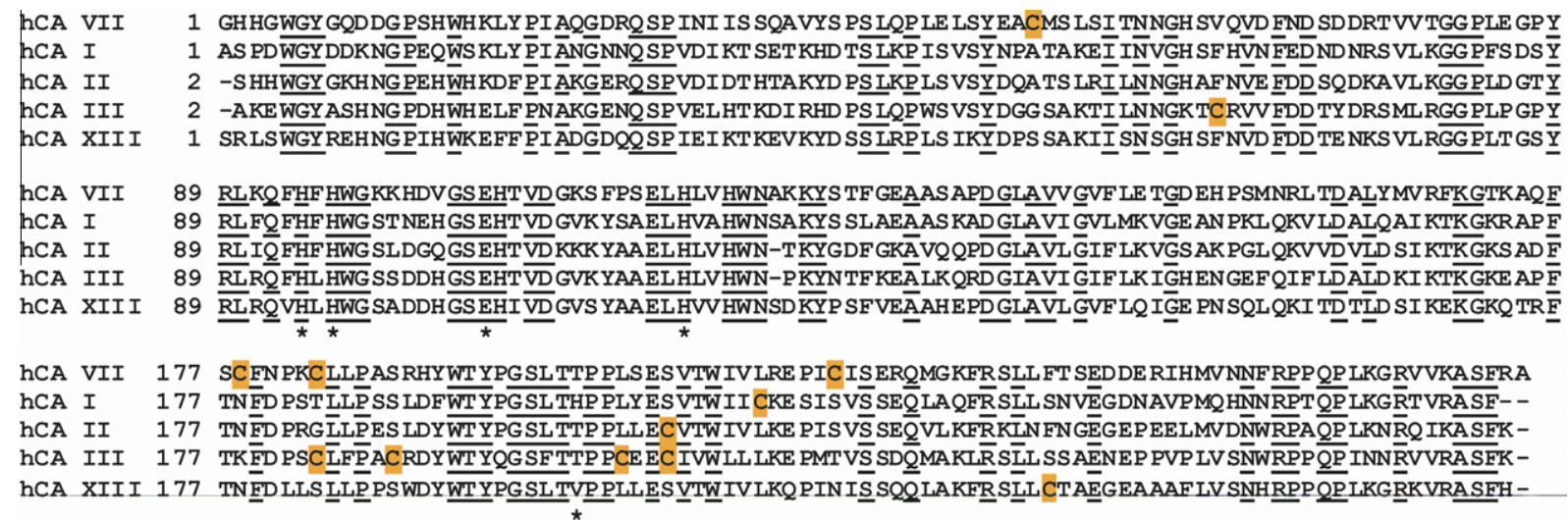

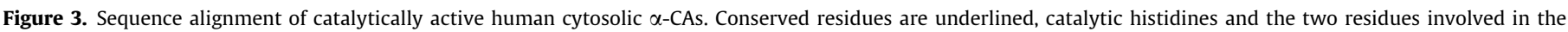
orientation of the substrate, Thr199 and Glu106, ${ }^{1-3}$ are indicated with asterisks, whereas the cysteine residues are highlighted in yellow.

Table 2

Kinetic parameters for the hydrolysis of 4-nitrophenyl acetate in the presence of cytosolic CA isoforms I, II, VII and XIII, at $\mathrm{pH} 7.4$ and $25^{\circ} \mathrm{C}$, and inhibition data with acetazolamide (5-acetamido-1,3,4-thiadiazole-2-sulfonamide)

\begin{tabular}{lllcl}
\hline Isozyme $^{*}$ & $k_{\text {cat }} / K_{\mathrm{M}}\left(\mathrm{M}^{-1} \mathrm{~s}^{-1}\right)$ & $K_{\mathrm{M}}(\mathrm{mM})$ & $\mathrm{IC}_{50}(\mathrm{AZA})(\mathrm{nM})$ & Ref. \\
\hline hCA I & $753 \pm 31$ & $3.025 \pm 0.014$ & $1210 \pm 76$ & 13 \\
hCA II & $2607 \pm 85$ & $30.53 \pm 2.10$ & $28 \pm 1.1$ & 13 \\
hCA III & $139 \pm 12$ & $1.234 \pm 0.013$ & $7840 \pm 230$ & $\mathrm{a}$ \\
mCA XIII & $7706 \pm 324$ & $1.132 \pm 0.015$ & $490 \pm 33$ & 113 \\
hCA VII & $(3.27 \pm 0.12) \times 10^{6}$ & $0.75 \pm 0.04$ & $357 \pm 12$ & $\mathrm{a}$ \\
C183S/C217S & $(4.20 \pm 0.18) \times 10^{6}$ & $1.06 \pm 0.08$ & $170 \pm 14$ & $\mathrm{a}$ \\
sgCA VII & $(2.39 \pm 0.10) \times 10^{6}$ & $0.50 \pm 0.05$ & $265 \pm 9$ & $\mathrm{a}$
\end{tabular}

The data are provided as the mean \pm standard deviation (from at least three different assays).

$\mathrm{h}=$ human, $\mathrm{m}=$ murine isoform.

a This work.

Table 3

Kinetic parameters for the hydrolysis of 4-nitrophenyl phosphate in the presence of cytosolic CA isoforms I, II and XIII, at pH 7.4 and $25^{\circ} \mathrm{C}$, and inhibition data with acetazolamide (5-acetamido-1,3,4-thiadiazole-2-sulfonamide)

\begin{tabular}{lllll}
\hline Isozyme $^{*}$ & $k_{\text {cat }} / K_{\mathrm{M}}\left(\mathrm{M}^{-1} \mathrm{~s}^{-1}\right)$ & $K_{\mathrm{M}}(\mathrm{mM})$ & $\mathrm{IC}_{50}(\mathrm{AZA})(\mathrm{nM})$ & Ref. \\
\hline hCA I & $65.55 \pm 5.2$ & $0.935 \pm 0.10$ & $330 \pm 14$ & 13 \\
hCA II & $14.89 \pm 0.54$ & $2.195 \pm 0.20$ & $63 \pm 5$ & 13 \\
hCA III & $45.32 \pm 3.76$ & $1.345 \pm 0.16$ & $6500 \pm 124$ & $\mathrm{a}$ \\
mCA XIII & $1374 \pm 62$ & $0.232 \pm 0.02$ & $1050 \pm 76$ & 13 \\
hCA VII & $(2.89 \pm 0.09) \times 10^{4}$ & $1.43 \pm 0.09$ & $3440 \pm 39$ & $\mathrm{a}$ \\
C183S/C217S & $(3.03 \pm 0.11) \times 10^{4}$ & $2.21 \pm 0.13$ & $2910 \pm 45$ & $\mathrm{a}$ \\
sgCA VII & $(3.04 \pm 0.11) \times 10^{4}$ & $0.97 \pm 0.05$ & $2520 \pm 49$ & $\mathrm{a}$ \\
\hline
\end{tabular}

The data are provided as the mean \pm standard deviation (from at least three different assays).

$\mathrm{h}=$ human, $\mathrm{m}=$ murine isoform.

a This work.

catalysts for the $\mathrm{CO}_{2}$ hydration reaction. Thus, there is not a clearcut parallelism between the catalytic activities of these isoforms for the various reactions that they catalyze.

The detailed kinetic studies on hCA VII and its mutated/glutationylated forms reported here indicate that the modification of Cys183 and/or Cys217 by glutathione does not have a relevant impact on the active site of the enzyme, causing rather small differences in the specific activity of these enzymes for $\mathrm{CO}_{2}$ hydration, as well as esterase and phosphatase activities. However, an important observation is that hCA VII and its variants are highly effective as esterases/phosphatases, compared to other cytosolic CA isoforms, such as CA I, II, III and XIII. These findings seem to indicated that the observed S-glutathionylated, if present in vivo, is not involved in the regulation of the enzyme's catalytic activity but rather, as already observed for hCA III, can help hCA VII to function as an oxygen radical scavenger to protect cells from oxidative damage. Indeed, it is worth noting that in vivo glutathione concentration is abundant, reaching millimolar concentration in most cell types, especially in liver, $27,41,42$ and could probably trigger the glutathionylation of CA VII. ${ }^{27}$ We also speculate that CA VII may act as an esterase/phosphatase in vivo, but this hypothesis should be verified and the eventual alternative substrates of this enzyme determined.

\section{Acknowledgments}

Research from our laboratories was financed by several EU projects (FP6, DeZnIT; and FP7, Metoxia).

\section{References and notes}

1. Supuran, C. T. Nat. Rev. Drug Disc. 2008, 7, 168.

2. Alterio, V.; Di Fiore, A.; D’Ambrosio, K.; Supuran, C. T.; De Simone, G. X-ray Crystallography of Carbonic Anhydrase Inhibitors and its Importance in Drug Design. In Drug Design of Zinc-Enzyme Inhibitors: Functional, Structural, and Disease Applications; Supuran, C. T., Winum, J.-Y., Eds.; Wiley: Hoboken, New Jersey, 2009; pp 73-138.

3. Supuran, C. T. Future Med. Chem. 2011, 3, 1165.

4. Supuran, C. T.; Conroy, C. W.; Maren, T. H. Proteins 1997, 27, 272.

5. Briganti, F.; Mangani, S.; Scozzafava, A.; Vernaglione, G.; Supuran, C. T. J. Biol. Inorg. Chem. 1999, 4, 528.

6. Guerri, A.; Briganti, F.; Scozzafava, A.; Supuran, C. T.; Mangani, S. Biochemistry 2000, 39, 12391.

7. Pocker, Y.; Dickerson, D. G. Biochemistry 1968, 7, 1995.

8. Pocker, Y.; Meany, J. E. Biochemistry 1967, 6, 239.

9. Pocker, Y.; Stone, J. T. Biochemistry 1967, 6, 668.

10. Verpoorte, J. A.; Mehta, S.; Edsall, J. T. J. Biol. Chem. 1967, 242, 4221.

11. Kaiser, E. T.; Lo, K. W. J. Am. Chem. Soc. 1969, 91, 4912.

12. Höst, G.; Mårtensson, L. G.; Jonsson, B. H. Biochim. Biophys. Acta 2006, 1764 1601.

13. Innocenti, A.; Scozzafava, A.; Parkkila, S.; Puccetti, L.; De Simone, G.; Supuran, C. T. Bioorg. Med. Chem. Lett. 2008, 18, 2267.

14. (a) Hilvo, M.; Innocenti, A.; Monti, S. M.; De Simone, G.; Supuran, C. T.; Parkkila, S. Curr. Pharm. Des. 2008, 14, 672; (b) Guzel, O.; Innocenti, A.; Scozzafava, A.; Salman, A.; Supuran, C. T. Bioorg. Med. Chem. Lett. 2009, 19, 3170; (c) Nishimori, I.; Minakuchi, T.; Onishi, S.; Vullo, D.; Cecchi, A.; Scozzafava, A.; Supuran, C. T. J. Enzyme Inhib. Med. Chem. 2009, 24, 70.

15. Ruusuvuori, E.; Li, H.; Huttu, K.; Palva, J. M.; Smirnov, S.; Rivera, C.; Kaila, K.; Voipio, J. J. Neurosci. 2004, 24, 2699.

16. Bootorabi, F.; Jänis, J.; Smith, E.; Waheed, A.; Kukkurainen, S.; Hytönen, V.; Valjakka, J.; Supuran, C. T.; Vullo, D.; Sly, W. S.; Parkkila, S. Biochimie 2010, 92, 1072.

17. Di Fiore, A.; Truppo, E.; Supuran, C. T.; Alterio, V.; Dathan, N.; Bootorabi, F. Parkkila, S.; Monti, S. M.; De Simone, G. Bioorg. Med. Chem. Lett. 2010, 20, 5023.

18. Thiry, A.; Dogné, J. M.; Supuran, C. T.; Masereel, B. Curr. Top. Med. Chem. 2007, 7, 855.

19. Asiedu, M.; Ossipov, M. H.; Kaila, K.; Price, T. J. Pain 2010, 148, 302.

20. Di Fiore, A.; Monti, S. M.; Hilvo, M.; Parkkila, S.; Romano, V.; Scaloni, A.; Pedone, C.; Scozzafava, A.; Supuran, C. T.; De Simone, G. Proteins 2008, 74, 164. 
21. (a) Analyses were performed using a 300 A narrow bore $250 \times 2 \mathrm{~mm}$ C4 Jupiter column (Phenomenex, Torrance, CA) with a gradient of solvent $\mathrm{B}(0.05 \%$ trifluoroacetic acid (TFA) in $\left.\mathrm{CH}_{3} \mathrm{CN}\right)$ on solvent $\mathrm{A}\left(0.08 \%\right.$ TFA in $\left.\mathrm{H}_{2} \mathrm{O}\right)$ that ranged from $30 \%$ to $70 \%$, over a period of $40 \mathrm{~min}$. Intact recombinant proteins were analyzed with a complete Surveyor HPLC system connected on line with a LCQ DecaXP Ion Trap mass spectrometer (ThermoElectron, USA) equipped with an OPTON electrospray source. (b) Titration of available cysteine sidechains of hCAVII was carried out using wild type enzyme purified in absence of GSH. hCAVII was alkylated with 4-vinylpyridine (4-VP) (Sigma) under denaturing non-reducing conditions, and subjected to LC-ESI-MS analysis. Data showed that protein harboured two molecules of 4-VP (MW 30311.4 $\pm 0.5 \mathrm{Da}$ ) confirming the presence of a disulfide bond. On the contrary, when protein was reduced before 4-VP alkylation the four cysteines resulted alkylated (MW $30521 \pm 0.5 \mathrm{Da})$

22. Papa, S.; Monti, S. M.; Vitale, R. M.; Bubici, C.; Jayawardena, S.; Alvarez, K.; De Smaele, E.; Dathan, N.; Pedone, C.; Ruvo, M.; Franzoso, G. J. Biol. Chem. 2007, 282, 19029

23. Tryptic proteolysis was carried out on $5 \mu \mathrm{g}$ protein incubated with TPCKtreated trypsin (Sigma-Aldrich, Milan) at an enzyme:substrate ratio of 1:100, in $50 \mu \mathrm{l}$ of a solution containing $50 \mathrm{mM}$ Tris. $\mathrm{HCl}(\mathrm{pH} \mathrm{7.5})$ at $37^{\circ} \mathrm{C}$ for $16 \mathrm{~h}^{24}$,

24. Tornatore, L.; Marasco, D.; Dathan, N.; Vitale, R. M.; Benedetti, E.; Papa, S.; Franzoso, G.; Ruvo, M.; Monti, S. M. J. Mol. Biol. 2008, 378, 97.

25. Protein tryptic digests were analysed on the same LC-MS apparatus described above, but were run on C18 BioBasic $30 \times 2 \mathrm{~mm}$ ID column (ThermoElectron, Milan), applying a gradient of Solvent B on Solvent A from $5 \%$ to $55 \%$, over a time period of $65 \mathrm{~min}$. Mass spectra were recorded continuously at mass intervals of 400-2000 amu, in positive mode and Data-Dependent Analysis (DDA) in order to fragment the eluted peptides and obtain sequence information. Fragmentation was induced on selected ions from 400 to $1200 \mathrm{amu}$, with a fixed 35\% of total radio-frequency.

26. Kadokura, H.; Katzen, F.; Beckwith, J. Annu. Rev. Biochem. 2003, 72, 111.

27. Filomeni, G.; Rotilio, G.; Ciriolo, M. R. Cell Death Differ. 2005, 12, 1555.

28. Chai, Y. C.; Jung, C. H.; Lii, C. K.; Ashraf, S. S.; Hendrich, S.; Wolf, B.; Sies, H.; Thomas, J. A. Arch. Biochem. Biophys. 1991, 284, 270.

29. Lii, C. K.; Wang, S. T.; Chen, H. W. Toxicol. Lett. 1996, 84, 97.

30. Rokutan, K.; Thomas, J. A.; Sies, H. Eur. J. Biochem. 1989, 179, 233.

31. Mallis, R. J.; Poland, B. W.; Chatterjee, T. K.; Fisher, R. A.; Darmawan, S.; Honzatko, R. B.; Thomas, J. A. FEBS Lett. 2000, 482, 237.

32. Zimmerman, U. J.; Wang, P.; Zhang, X.; Bogdanovich, S.; Forster, R. IUBMB Life 2004, 56, 343

33. Räisänen, S. R.; Lehenkari, P.; Tasanen, M.; Rahkila, P.; Härkönen, P. L.; Väänänen, H. K. FASEB J. 1999, 13, 513.

34. Roy, P.; Reavey, E.; Rayne, M.; Roy, S.; Abed El Baky, M.; Ishii, Y.; Bartholomew, C. FEBS J. 2010, 277, 441.

35. An SX.18MV-R Applied Photophysics (Oxford, UK) stopped-flow instrument has been used to assay the catalytic/inhibition of various CA isozymes according to Khalifa's method ${ }^{36}$ Phenol Red (at a concentration of $0.2 \mathrm{mM}$ ) has been used as indicator, working at the absorbance maximum of $557 \mathrm{~nm}$ with $10 \mathrm{mM}$ Hepes ( $\mathrm{pH} 7.5$ ) as buffer, $0.1 \mathrm{M} \mathrm{Na}_{2} \mathrm{SO}_{4}$ (for maintaining constant the ionic strength; these anions are not inhibitory in the used concentration), following the initial rates of the $\mathrm{CA}$-catalyzed $\mathrm{CO}_{2}$ hydration reaction for period of $10-100 \mathrm{~s}$. The $\mathrm{CO}_{2}$ concentrations ranged from 1.7 to $17 \mathrm{mM}$ for the determination of the kinetic parameters and inhibition constants. For each inhibitor at least six traces of the initial $5-10 \%$ of the reaction have been used for determining the initial velocity. Stock solutions of inhibitors were prepared at a concentration of $10 \mathrm{mM}$ (in DMSO-water $1: 1, \mathrm{v} / \mathrm{v}$ ) and dilutions up to $1 \mathrm{nM}$ done with the assay buffer mentioned above. At least 7 different inhibitor concentrations have been used for measuring the inhibition constant. Inhibitor and enzyme solutions were preincubated together for $10 \mathrm{~min}$ at room temperature prior to assay, in order to allow for the formation of the E-I complex. Triplicate experiments were done for each inhibitor concentration, and the values reported throughout the paper are the mean of such results. The inhibition constants were obtained by non-linear least-squares methods using PRISM 3 and represent the mean from at least three different determinations.

36. Khalifah, R. G. J. Biol. Chem. 1971, 246, 2561.

37. 4-Nitrophenyl acetate hydrolysis was monitored by measuring the absorbance at $405 \mathrm{~nm}$ of the chromogenic group 4-nitrophenol which is released by the hydrolytic process (extinction coefficient of $10,510 \mathrm{M}^{-1}$ ). Reactions were performed at $25^{\circ} \mathrm{C}$ in a quartz cuvette with $1 \mathrm{~cm}$ lightpath, using a Perkin Elmer Lambda Bio20 UV-VIS spectrometer. Enzyme concentrations were between $0.10-5.0 \mu \mathrm{M}$ and substrate concentration between $0.08-0.37 \mathrm{mM}$. The substrate was dissolved in freshly distilled acetonitrile and diluted with buffer (10 mM HEPES and $10 \mathrm{mM}$ TRIS, pH 7.4, maintaining the ionic strength constant by addition of $0.1 \mathrm{M}$ sodium sulfate, in such a way that the final concentration of $\mathrm{MeCN}$ was of $5 \%$ ). Kinetic parameters were determined (in cases in which the substrate solubility allowed this, i.e., concentrations of substrate ester of $0.3-5.0 \mathrm{mM}$ ) by fitting the data to the Michaelis-Menten model (Eq. 1):

$V_{\mathrm{o}}=\left(k_{\mathrm{cat}}[\mathrm{E}]_{0}[\mathrm{~S}]_{0}\right) /\left([\mathrm{S}]_{0}+K_{\mathrm{M}}\right)$

Otherwise, $k_{\text {cat }} / K_{\mathrm{M}}$ values were derived from a linear fit (Eq. 2) by using PRISM

$V_{\mathrm{o}}=[\mathrm{E}]_{0}[\mathrm{~S}]_{0}\left(k_{\text {cat }} / K_{\mathrm{M}}\right)$

At least three independently repeated measurements have been done for each enzyme, at five different substrate concentrations, of $0.3,0.9,1.7,2.6$ and $4.5 \mathrm{mM}$.

The rates of spontaneous hydrolysis (without enzyme) were subtracted from the enzymatic rates. Inhibition with acetazolamide has been used as a control, being performed as described above, by titration of the enzymes with acetazolamide solutions in concentration ranges between $10 \mathrm{nM}$ and $100 \mu \mathrm{M} . \mathrm{IC}_{50}$ represents the molarity of inhibitor producing a 50\% decrease of the enzyme activity and were determined from semilogarithmic plots of enzyme activity vs. molarity of inhibitor. ${ }^{7}$ At least 6 different inhibitor concentrations have been used, ranging from $10 \mu \mathrm{M}, 1 \mu \mathrm{M}, 0.1 \mu \mathrm{M} ; 0.01 \mu \mathrm{M} ; 50 \mathrm{nM}$ to $10 \mathrm{nM}$. Protein concentrations were determined according to the Bradford method (Bradford, M. Anal. Biochem. 1976, 72, 248-254) and the molecular weight of the proteins was determined by high resolution MS

The phosphatase activity with 4-nitrophenyl phosphate as substrate has been assayed by a variant of the method used by Pullan and Noltmann, measuring the absorbance at $405 \mathrm{~nm}$ of the chromogenic group 4-nitrophenol which is released according to the hydrolytic process. The assay has been performed at $25{ }^{\circ} \mathrm{C}$ (not at $30^{\circ} \mathrm{C}$ ) in the same buffer used for the esterase activity measurements described above, working at substrate concentrations of $0.08-5 \mathrm{mM}$. Kinetic parameters were determined as described above, and the rates of spontaneous hydrolysis (without enzyme) were subtracted from the measured enzymatic rates. Inhibition with acetazolamide has again been used as a control, being performed as described above, by titration of the enzymes with acetazolamide solutions in the concentration range between $10 \mathrm{nM}$ to $100 \mu \mathrm{M}$. $\mathrm{IC}_{50}$ values were calculated as described above. The sulfatase activity with 4-nitrophenyl sulphate as substrate, has also been investigated in an analogous manner and working at various $\mathrm{pH}$ values (in the range of 5.4-8.5, data not shown) but was totally absent with all investigated enzymes, in all experimental conditions employed. ${ }^{39}$ At least three independently repeated measurements have been done for each enzyme, at five different substrate concentrations, of $0.3,0.9$, 1.7, 2.6 and $4.5 \mathrm{mM}$. At least 6 different inhibitor concentrations have been used, ranging from $10 \mu \mathrm{M}, 1 \mu \mathrm{M}, 0.1 \mu \mathrm{M} ; 0.01 \mu \mathrm{M} ; 50 \mathrm{nM}$ to $10 \mathrm{nM}$.

38. Pullan, L. M.; Noltmann, E. A. Biochemistry 1985, 24, 635.

39. C183S/C217S mutant was cloned and expressed similarly to wild type enzyme Protein purification was carried out on a GSTrap and digestion with thrombin occurred after its elution from GSTrap. The presence of the mutations was confirmed both by sequencing the clones and by mass spectrometry of the purified protein; the latter confirmed that no mass increment occurred on the sample. As attended the observed mw of $30068.23 \pm 0.5$ Da was in agreement with the theoretical value of $30068.72 \mathrm{Da}$. The absence of the reactive cysteines was further confirmed by 4-VP alkylation experiments. In fact, denatured and alkylated C183S/C217S mutant showed attended mw of 30068.23 $\pm 0.5 \mathrm{Da}$. On the contrary denatured, reduced and alkylated double mutant, showed an increase of $210 \mathrm{Da}$, corresponding to the incorporation of two 4-VP moieties thus confirming the occurrence of a disulfide bond also on this variant species. CA III and the other isoforms were recombinant proteins obtained as described earlier. ${ }^{13,14}$

40. Vullo, D.; Voipio, J.; Innocenti, A.; Rivera, C.; Ranki, H.; Scozzafava, A.; Kaila, K.; Supuran, C. T. Bioorg. Med. Chem. Lett. 2005, 15, 971.

41. Marí, M.; Morales, A.; Colell, A.; García-Ruiz, C.; Fernández-Checa, J. C. Antioxid. Redox Signal. 2009, 11, 2685.

42. Marí, M.; Colell, A.; Morales, A.; von Montfort, C.; Garcia-Ruiz, C.; FernándezCheca, J. C. Antioxid. Redox Signal. 2010, 12, 1295. 